\title{
Regulatory T cells and the induction of IL-17
}

\author{
A Kitani ${ }^{1}$ and $\mathrm{L} \mathrm{Xu}{ }^{1}$
}

T helper (Th)17 cells have been shown to play a role in the pathogenesis of inflammatory and autoimmune diseases including inflammatory bowel diseases (IBD). It is now well established that although transforming growth factor (TGF)- $\beta$ alone induces FoxP3 ${ }^{+}$regulatory T (Treg) cells, TGF- $\beta$ and interleukin (IL)-6, acting in concert, induce differentiation of mouse naive T cells into Th17. As we previously showed that CD4+CD25+Foxp3+ "natural" Treg cells express cell surface or secrete TGF- $\beta$, we examined whether Treg cells serve to induce Th17 differentiation. We found that upon activation, Treg cells induce CD4 ${ }^{+} \mathrm{CD} 25^{-}$naive T cells or Treg cells themselves to differentiate into Th17 in the presence of IL- 6 alone without exogenous addition of TGF- $\beta$. We also found that TGF- $\beta$ is also produced by dendritic cells that are in contact with Treg cells. Although Treg cells are effectively recruited at inflamed mucosa in patients with IBD, it is possible that Treg cells may have undesirable effects through their ability to differentiate into pathogenic Th17 in the presence of IL-6 and/or IL-23 at sites of inflammation. Further study of the relationship between Treg cells and Th17 cells in the inflamed tissue in IBD is important for possible Treg cell-mediated therapeutic applications.

\section{TH17-CELL DIFFERENTIATION ANDTGF- $\beta$}

Thelper (Th)17 cells have been shown to play a role in the pathogenesis of inflammatory and autoimmune diseases such as the inflammatory bowel diseases (IBD). ${ }^{1,2}$ It is now well established that although transforming growth factor (TGF)- $\beta$ alone induces FoxP3 ${ }^{+}$regulatory T (Treg) cells, TGF- $\beta$, and interleukin (IL)-6, acting in concert, induce the differentiation of mouse naive T cells into Th17 cells by upregulating the retinoidrelated orphan receptor- $\gamma \mathrm{t} .{ }^{3-6}$ As we previously reported that $\mathrm{CD} 4{ }^{+} \mathrm{CD} 25^{+}$Foxp 3 + "natural" Treg cells express cell surface or secrete TGF- $\beta$ in both mouse and human Tregs, our findings prompted us to investigate the possibility that Treg cells play a role in such Th17 differentiation. ${ }^{7,8}$

\section{CD25+FOXP3+ BUT NOT CD25+FOXP3- T CELLS EXPRESS SURFACE TGF- $\beta$}

In an earlier study, we observed that $\mathrm{CD} 4{ }^{+} \mathrm{CD} 25^{+}$Treg cells stained with anti-latent-associated peptide antibody were also FoxP3-positive using confocal fluorescence microscopy. ${ }^{9}$ Latent-associated peptide-positive staining suggests the expression of a latent form of membrane TGF- $\beta$ on Treg, not the active TGF- $\beta$ bound to the TGF- $\beta$ receptors on Treg cells. In contrast, $\mathrm{CD} 4{ }^{+} \mathrm{CD} 25^{-} \mathrm{T}$ cells were mostly negative in both latent-associated peptide and FoxP3 staining. After stimulation with anti-CD3 and anti-CD28 antibodies, activated Treg cells exhibited strongly enhanced latent-associated peptide stain- ing, which could be expected to exhibit a stronger effect on membrane TGF- $\beta$-mediated Th17 differentiation of $\mathrm{CD} 4{ }^{+} \mathrm{CD} 25^{-} \mathrm{T}$ cells.

\section{CD4 + CD25 + FOXP3 + TREG CELLS INDUCE CD4 + CD25- CELLSTO BECOME IL-17-PRODUCING CELLS}

To facilitate the analysis of IL-17 differentiation mediated by FoxP $3^{+}$Treg cells, we used green fluorescent protein (GFP) knock-in mice kindly provided by Mohamed Oukka (Center of Neurologic Diseases, Harvard Medical School), in which IRESGFP is inserted downstream of the stop codon of FoxP3 gene. ${ }^{5}$ Using this GFP knock-in mouse, we found that addition of IL-6 alone (without TGF- $\beta$ ) to the coculture of fresh $\mathrm{CD} 4^{+} \mathrm{GFP}^{+}$ T cells with $\mathrm{CD} 4{ }^{+} \mathrm{GFP}^{-}$T cells obtained by flow cytometric cell sorting led to the appearance of a low number of IL-17positive cells at a $1: 1$ cell $\left(\mathrm{GFP}^{+} / \mathrm{GFP}^{-}\right)$ratio $(1.8 \%)$ and a somewhat increased number of these at a $2: 1$ ratio $(5.8 \%)$, whereas addition of IL- 6 to the coculture of preactivated CD $4^{+}$FoxP3 ${ }^{+}$ $\mathrm{T}$ cells with fresh $\mathrm{CD} 4^{+}$FoxP3 ${ }^{-} \mathrm{T}$ cells led to a cell population containing approximately $25.9 \%$ IL-17-producing cells at a 1:1 cell ratio without exogenous addition of TGF- $\beta$, but the coculture of preactivated $\mathrm{CD} 4^{+} \mathrm{FoxP}^{-} \mathrm{T}$ cells led to a cell population containing virtually no IL-17-producing cells (Figure 1 and ref. 10). Induction of IL-17-producing cells by preactivated $\mathrm{CD} 4{ }^{+}$FoxP3 ${ }^{+}$T cells with IL- 6 alone without exogenous TGF- $\beta$ was also confirmed by the detection of IL-17 in the

${ }^{1}$ Mucosal Immunity Section, Laboratory of Host Defenses, National Institute of Allergy and Infectious Diseases, Bethesda, Maryland, USA. Correspondence: A Kitani (akitani@niaid.nih.gov) 

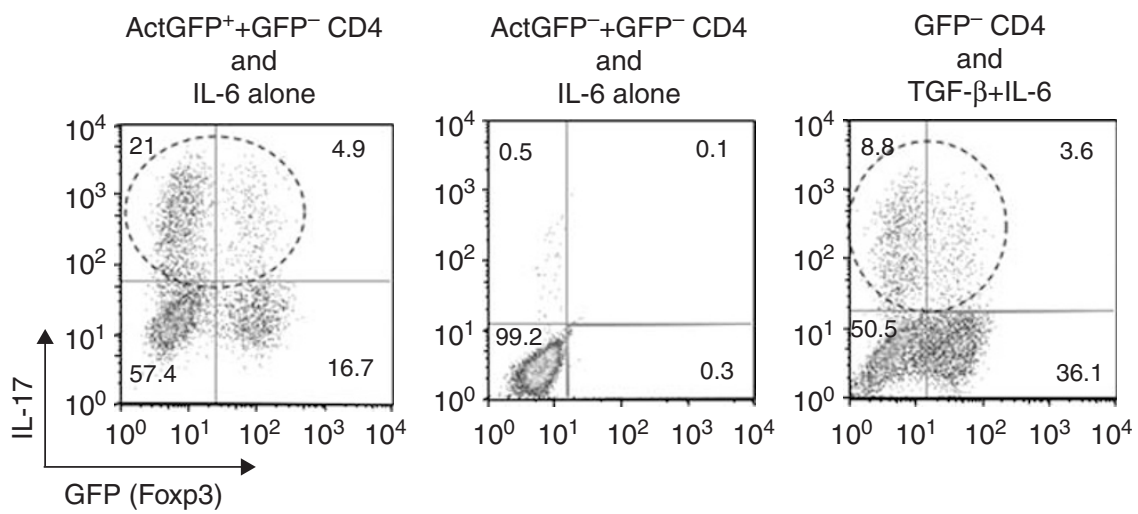

Figure 1 Coculture of preactivated $\mathrm{CD}^{+}{ }^{+} \mathrm{GFP}+\left(\mathrm{FoxP}^{+}\right) \mathrm{T}$ cells with fresh $\mathrm{CD}^{+}{ }^{+} \mathrm{GFP}^{-}\left(\mathrm{FoxP}^{-}\right) \mathrm{T}^{-}$cells with IL-6 alone led GFP- $\left(\right.$FoxP3 $\left.{ }^{-}\right) \mathrm{T}^{-}$cells to IL-17-producing cells (as in dotted circle), whereas the coculture of preactivated CD4 ${ }^{+} \mathrm{GFP}^{-}\left(\mathrm{FoxP}^{-}\right) \mathrm{T}^{\mathrm{T}}$ cells led fresh $\mathrm{CD}^{+}{ }^{+}$FoxP3 ${ }^{-} \mathrm{T}^{-}$cells to virtually no IL-17-producing cells. Cells were collected and analyzed on day 4. GFP, green fluorescent protein; IL, interleukin.

supernatant by enzyme-linked immunosorbent assay. Interestingly, stimulation of $\mathrm{CD}^{-}{ }^{-} \mathrm{FoxP} 3^{-} \mathrm{T}$ cells with recombinant TGF- $\beta\left(3 \mathrm{ng} \mathrm{ml}^{-1}\right)$ and IL-6, gave rise to a cell population containing only $12 \%$ IL-17-producing cells, indicating that Treg cells were more efficient than exogenous TGF- $\beta$ in inducing IL-17-producing cells. This induction of IL-17-producing cells by preactivated $\mathrm{CD} 4{ }^{+} \mathrm{CD} 25^{+} \mathrm{Foxp} 3^{+}$T cells was TGF- $\beta$ dependent, because the addition of TGF- $\beta$ RI (ALK5) kinase inhibitor led to dramatically decreased induction of IL-17-positive $\mathrm{T}$ cells and increased induction of interferon- $\gamma$-producing cells. Finally, we found that upon restimulation, purified preactivated $\mathrm{CD}^{+}{ }^{+} \mathrm{CD} 25^{+}$Treg cells (or sorted GFP ${ }^{+} \mathrm{T}$ cells obtained from FoxP3-GFP knock-in mice) released large amounts of both the active and total TGF- $\beta$ into the culture supernatant, as assessed by enzyme-linked immunosorbent assay. ${ }^{10}$

\section{CD4 ${ }^{+}$CD25+FOXP3 ${ }^{+}$TREG CELLS THEMSELVES DIFFERENTIATE INTO IL-17-PRODUCING CELLS}

More important than the finding that Treg cells induce naive $\mathrm{CD} 4{ }^{+} \mathrm{CD} 25^{-} \mathrm{T}$-cell differentiation into IL-17-producing cells, is the finding that $\mathrm{CD} 4{ }^{+} \mathrm{CD} 25^{+} \mathrm{Foxp}^{+}\left(\mathrm{GFP}^{+}\right) \mathrm{T}$ cells themselves differentiate into Th17 cells in the presence of IL- 6 (and in the absence of exogenous TGF- $\beta$ ) upon activation of antiCD3/anti-CD28.

Thus, as shown in Figure 2, we found that the culture of $\mathrm{CD} 4{ }^{+} \mathrm{CD} 25^{+} \mathrm{Foxp}^{+}\left(\mathrm{GFP}^{+}\right) \mathrm{T}$ cells under these conditions gave rise to a cell population containing $20 \%$ IL-17-producing $\mathrm{T}$ cells, whereas the culture of $\mathrm{CD} 4^{+} \mathrm{CD} 25^{-} \mathrm{Foxp}^{-}\left(\mathrm{GFP}^{-}\right) \mathrm{T}$ cells under the same conditions gave rise to a population containing only $0.4 \%$ IL- 17 -producing cells. ${ }^{10}$ Of interest, the percentages of both IL-17 single positive and GFP/IL-17 double positive cells increase during the culture period, suggesting that Foxp3positive cells can co-express IL-17 and that IL-17 single positive cells pass through a Foxp3/IL-17 double positive stage.

In further studies, we determined the cellular source of TGF- $\beta$ in these cultures by intracellular staining with anti-TGF- $\beta$. As shown in Figure 3, the GFP ${ }^{+}$Treg cell population contained a
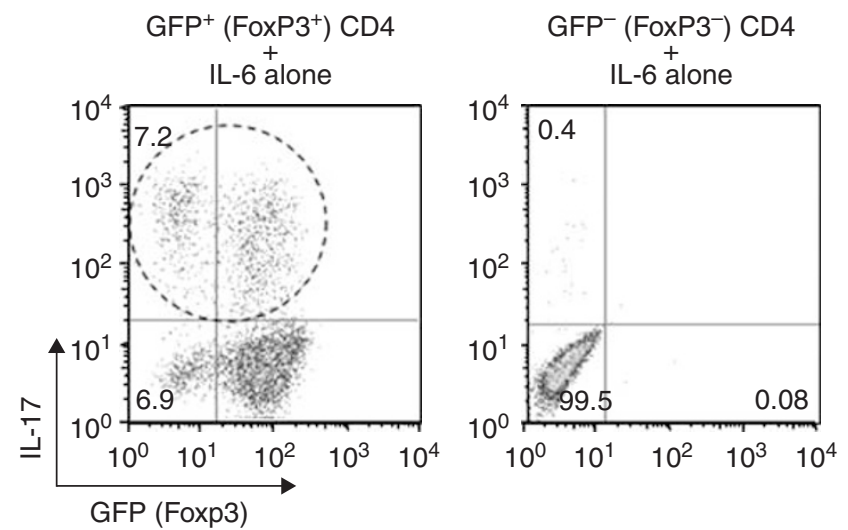

Figure $2 \mathrm{CD}^{+}{ }^{+} \mathrm{GFP}^{+}\left(\mathrm{FoxP}^{+}\right) \mathrm{T}$ cells, but not $\mathrm{CD} 4{ }^{+} \mathrm{GFP}^{-}\left(\mathrm{FoxP}^{-}\right)$ T cells became IL-17-producing cells (as in dotted circle) on day 6 after stimulation with anti-CD3/anti-CD28 and IL-6. GFP, green fluorescent protein; IL, interleukin.

subpopulation of TGF- $\beta$-containing cells that was larger and more intensely stained than that in the $\mathrm{CD}^{+} \mathrm{GFP}^{-} \mathrm{T}$ cell population..$^{10}$ In addition, the dendritic cell (DC) population also contained a TGF- $\beta$-positive subpopulation and when these cells were co-cultured with GFP ${ }^{+}$Treg cells, the TGF- $\beta$-positive subpopulation was greatly increased. Thus, Treg cells augment the induction of IL-17-producing cells in two ways: they produce TGF- $\beta$ themselves and they induce DCs to produce increased amounts of TGF- $\beta$. The latter point is important, as during the amelioration of established colitis Treg cells have been shown to be located between clusters of $\mathrm{CD} 11 \mathrm{c}^{+}$cells and pathogenic $\mathrm{T}$ cells, and thus in contact with both cell types. ${ }^{11}$ In addition, in a study of nonobese diabetic mice, using two photon laser-scanning microscopy to analyze priming of diabetogenic $\mathrm{T}$ cells and their control by Treg cells, it was found that Treg cells did not form detectable stable associations with Th cells, but did form stable associations with DCs bearing islet antigen. ${ }^{12}$ These studies delineate the importance of interaction between Treg cells and DCs in vivo and thus establish the possibility that Treg cells induce DCs to produce TGF- $\beta$. 

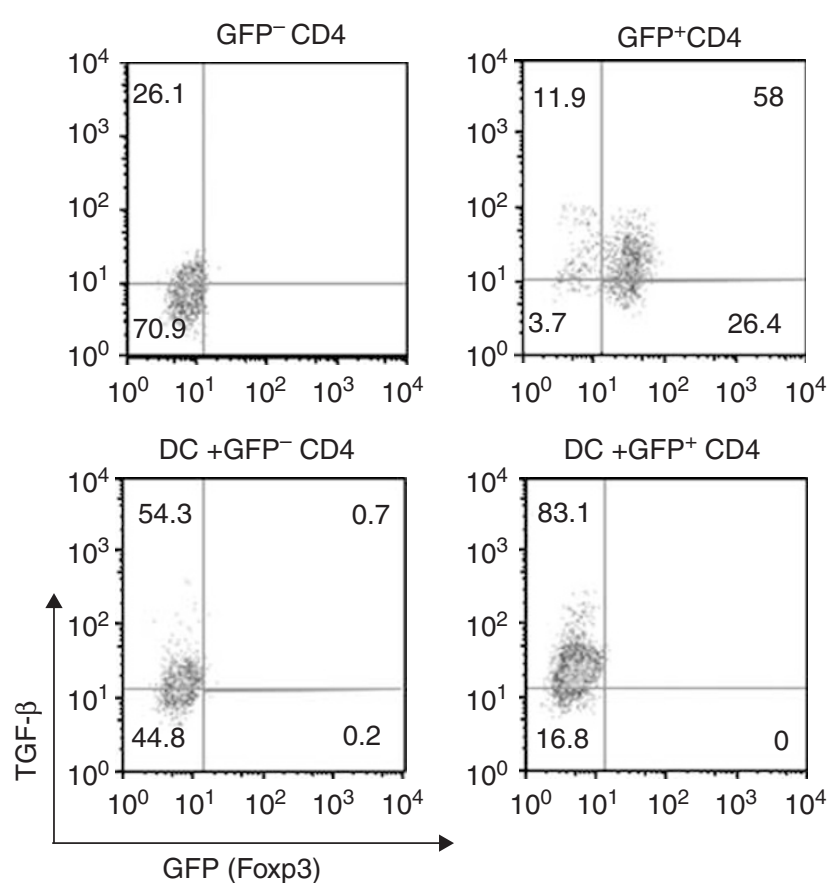

Figure $3 \mathrm{CD}^{+}{ }^{+} \mathrm{GFP}^{+}\left(\mathrm{FoxP}^{+}\right)$T cells, but not $\mathrm{CD} 4^{+} \mathrm{GFP}^{-}\left(\mathrm{FoxP}^{-}\right)$ $T$ cells, cocultured with bone marrow derived-DC with the stimulation of anti-CD3, and LPS induced strong expression of TGF- $\beta$ in CD4 ${ }^{+}$GFP+ $\left(F_{0 x P}{ }^{+}\right)$T cells and CD4-GFP- DCs. Cells were collected and analyzed on day 5. DC, dendritic cells; GFP, green fluorescent protein; LPS, lipopolysaccharide.

\section{THE POSSIBLE ROLE OFTREG DIFFERENTIATION INTO TH17 CELLS IN COLITIS MODELS AND IN HUMAN IBD}

Our finding that Treg cells induce the differentiation of $\mathrm{CD} 4{ }^{+} \mathrm{CD} 25^{-} \mathrm{T}$ cells into Th17 cells or self-induce into Th17 cells was further studied in 2,4,6-trinitrobenzenesulfonic acid colitis, a mouse model of human colitis. The available data showed that mice develop a more severe 2,4,6-trinitrobenzenesulfonic acid colitis accompanied by increased IL-17 production when they were administered Foxp $3^{+}\left(\mathrm{GFP}^{+}\right)$ Treg cells during the development of colitis. These data provide preliminary support for the idea that Treg cells contribute to Th17 differentiation in vivo under inflammatory conditions and therefore could be playing a role in the course of the inflammation.

Recently, the conditions necessary for the differentiation of human Th17 have been reported. In contrast to the murine system, human Th17 differentiation was induced by IL- $1 \beta$ and IL- 23 and enhanced by IL- 6 but was suppressed by TGF- $\beta$ and IL-12. ${ }^{13,14}$ In keeping with this, our preliminary findings suggest that human Treg cells can be induced to a Th17 state by IL-6 and IL- $1 \beta$.

\section{SIGNIFICANCE OF TH17 CELLS INDUCED BY AND/OR CONVERTED FROMTREG CELLS}

A summary of our findings relating to Treg cell-mediated Th17 differentiation is provided in Figure 4. What is the significance of Th17 cells induced by and/or converted from Treg cells?

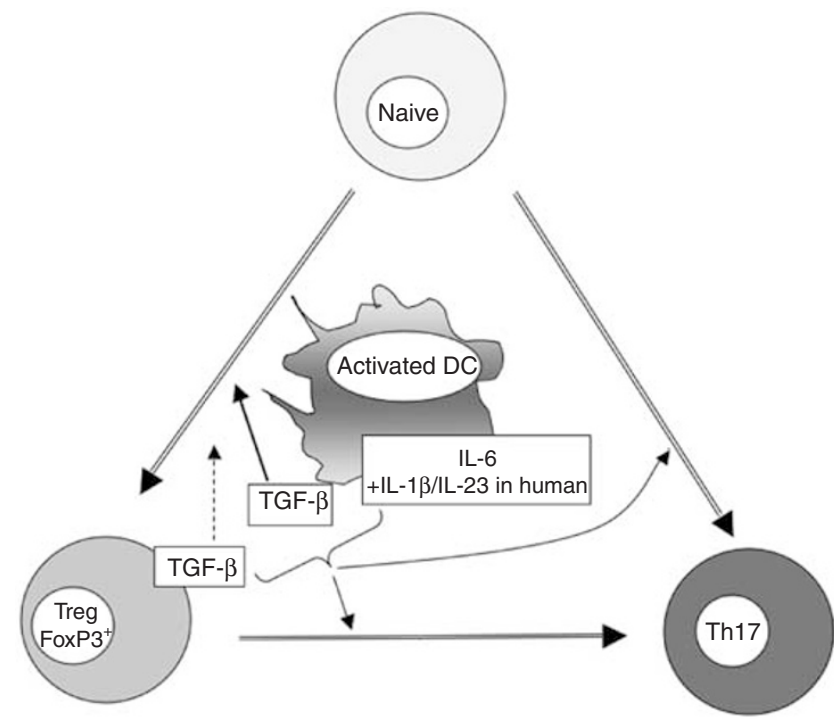

Figure 4 Treg cells induce $\mathrm{CD} 4{ }^{+} \mathrm{CD} 25^{-}$naive $\mathrm{T}$ cells or themselves to differentiate into Th17 by TGF- $\beta$ expressed on the cell surface of Treg cells and IL-6 (plus IL-1b and IL-23 in human) produced by activated DCs in the inflammatory condition. TGF- $\beta$ is also produced by DCs that are contacted with Treg cells. DC, dendritic cells; IL, interleukin; TGF- $\beta$, transformin growth factor- $\beta$; Th, T helper cell; Treg, regulatory T cells.

One possibility is that Treg cells contribute to the differentiation of Th17 cells and the latter, in turn, produce IL-17 and IL-22 cytokines that help to maintain mucosal barrier function. ${ }^{15}$ These cells, therefore help to maintain mucosal homeostasis in the absence of infection and improve the host defense response in the presence of infection. Another possibility is that the interconversion of Treg cells and Th17 has undesirable effects. Here, it should be noted that both $\mathrm{CD} 4{ }^{+} \mathrm{CD} 25^{+}$and $\mathrm{CD} 4{ }^{+} \mathrm{CD} 25^{\text {bright }} \mathrm{T}$ cells in the lamina propria were found to be significantly increased in patients with active Crohn's disease or active ulcerative colitis as compared with normal individuals. ${ }^{16,17}$ Although these Treg cells have been shown to possess suppressive activity in in vitro suppression assay, it is possible that some of these Treg cells may make an undesirable contribution to the differentiation of pathogenic Th17, especially as they exist in a milieu that contains the cytokines (such as IL-6, IL-1 $\beta$, and IL-23) that can convert them into Th17 cells. Recently, it was shown that although TGF- $\beta$ and IL- 6 drive initial Th17 lineage commitment, the pathogenic potential of Th17 cells are restrained by the coproduction of IL-10. Only when the Th17 cells are exposed to IL-23 they cease IL-10 production and attain their full pathogenic function. ${ }^{18}$ Whether or not Th17 cells in any state of differentiation can be converted into Treg cells remains to be seen. Clearly, further study of the relationship between Treg cells and Th17 cells in the inflamed tissue of IBD patients is important to the understanding of the consequences of Treg cell administration in the treatment of inflammatory diseases.

\section{ACKNOWLEDGMENTS}

The authors thank Drs Warren Strober and Ivan Fuss for their valuable discussion and help. 


\section{DISCLOSURE}

The authors have declared no financial interests.

() 2008 Society for Mucosal Immunology

\section{REFERENCES}

1. Park, H. et al. A distinct lineage of CD4 T cells regulates tissue inflammation by producing interleukin 17. Nat. Immunol. 6, 1133-1141 (2005).

2. Fuss, I.J. et al. Both IL-12p70 and IL-23 are synthesized during active Crohn's disease and are down-regulated by treatment with anti-IL-12 p40 monoclonal antibody. Inflamm. Bowel Dis. 12, 9-15 (2006).

3. Fantini, M.C., Becker, C., Monteleone, G., Pallone, F., Galle, P.R. \& Neurath, M.F. Cutting edge: TGF-beta induces a regulatory phenotype in CD4+CD25 - T cells through Foxp3 induction and down-regulation of Smad7. J. Immunol. 172, 5149-5153 (2004).

4. Veldhoen, M. Hocking, R.J., Atkins, C.J., Locksley, R.M., \& Stockinger, B. TGF-b in the context of an inflammatory cytokine milieu supports de novo differentiation of IL-17-producing T cells. Immunity 24, 179-189 (2006).

5. Bettelli, E. et al. Reciprocal developmental pathways for the generation of pathogenic effector TH17 and regulatory T cells. Nature 441, 235-238 (2006).

6. Ivanov, I.I. et al. The orphan nuclear receptor RORgammat directs the differentiation program of proinflammatory IL-17+ T helper cells. Cell 126, 1121-1133 (2006).

7. Nakamura, K., Kitani, A. \& Strober, W. Cell contact-dependent immunosuppression by CD4(+)CD25(+) regulatory $T$ cells is mediated by cell surface-bound transforming growth factor beta. J. Exp. Med. 194, 629-644 (2001).
8. Nakamura, K. et al. TGF-beta 1 plays an important role in the mechanism of CD4+CD25+ regulatory $T$ cell activity in both humans and mice. J. Immunol. 172, 834-842 (2004).

9. Oida, T., Xu, L., Weiner, H.L., Kitani, A. \& Strober, W. TGF-beta-mediated suppression by CD4+CD25+ T cells is facilitated by CTLA-4 signaling. J. Immunol. 177, 2331-2339 (2006).

10. Xu, L., Kitani, A., Fuss, I. \& Strober, W. Cutting edge: regulatory T cells induce CD4+CD25 - Foxp3- T cells or are self-induced to become Th17 cells in the absence of exogenous TGF-beta. J. Immunol. 178, 6725-6729 (2007).

11. Mottet, C., Uhlig, H.H. \& Powrie, F. Cutting edge: cure of colitis by CD4+CD25+ regulatory T cells. J. Immunol. 170, 3939-3943 (2003).

12. Tang, Q. et al. Visualizing regulatory $T$ cell control of autoimmune responses in non-obese diabetic mice. Nat. Immunol. 7, 83-92 (2005).

13. Acosta-Rodriguez, E.V., Napolitani, G., Lanzavecchia, A., \& Sallusto, F. Interleukins 1 beta and 6 but not transforming growth factor-beta are essential for the differentiation of interleukin 17-producing human Thelper cells. Nat. Immunol. 8, 942-949 (2007).

14. van Beelen, A.J. et al. Stimulation of the intracellular bacterial sensor NOD2 programs dendritic cells to promote interleukin-17 production in human memory T cells. Immunity 27, 660-669 (2007).

15. Mangan, P.R. et al. Transforming growth factor-beta induces development of the $\mathrm{T}(\mathrm{H}) 17$ lineage. Nature 441, 231-234 (2006).

16. Makita, S. et al. CD4+CD25 bright T cells in human intestinal lamina propria as regulatory cells. J. Immunol. 173, 3119-3130 (2004).

17. Uhlig, H.H. et al. Characterization of Foxp3+CD4+CD25+ and IL-10-secreting CD4+CD25+ T cells during cure of colitis. J. Immunol. 177, 5852-5860 (2006).

18. McGeachy, M.J. et al. TGF-beta and IL-6 drive the production of IL-17 and IL-10 by $T$ cells and restrain $T(H)-17$ cell-mediated pathology. Nat. Immunol. 8, 1390-1397 (2007). 